\title{
IMPROVED METHOD TO OBTAIN PFAFFIC ACID AS A MARKER FOR QUALITY CONTROL
}

\author{
Marili Villa Nova Rodrigues, Amanda Vedovello, Rodney Alexandre Ferreira Rodrigues*, Ilio Montanari Junior e Vera \\ Lucia Garcia Rehder \\ Centro Pluridisciplinar de Pesquisas Químicas, Biológicas e Agrícolas, Universidade Estadual de Campinas, CP 6171, 13081-970 \\ Campinas - SP, Brasil
}

Recebido em 7/9/12; aceito em 29/11/12; publicado na web em 8/3/13

\begin{abstract}
Pfaffic acid, a marker of Hebanthe eriantha (Brazilian ginseng), was first isolated in 1983 but is not yet commercially available. This lack of availability compromises the quality control of this plant and its derivatives. This paper proposes a process for pfaffic acid isolation from roots of $H$. eriantha at a purity suitable for analytical purposes. The steps involved in this process included extraction, hydrolysis, fractionation and purification by preparative HPLC. This process led to isolation of pfaffic acid with a chromatographic purity of $98.5 \%$ in a $0.25 \%$ yield from dried roots of $H$. eriantha; this yield is more than forty times higher than that of the current method in the literature.
\end{abstract}

Keywords: pfaffic acid; Hebanthe eriantha; Pfaffia paniculata.

\section{INTRODUCTION}

The commercial availability of reference products derived from natural products is the starting point for the development of analytical methods for quality control. In this context, the large Brazilian biodiversity contrasts with the few studies that have been performed on its native species. An example is Hebanthe eriantha, Brazilian ginseng, which has no analytical method for the determination of its active component, pfaffic acid.

The chemical structure of pfaffic acid was established in 1983 from the hydrolyzed extract obtained from the roots of this plant. ${ }^{1}$ Despite the widespread use of this species for its confirmed pharmacological effects, ${ }^{2-7}$ the unavailability of commercial pfaffic acid significantly compromises its quality control. $H$. eriantha is a very restricted species that is obtained by extractivism, and it is slow growing and difficult to propagate, leading to the marketing of other species as $H$. eriantha.

Chemically, approximately $11 \%$ of $H$. eriantha metabolites consist of the triterpene pfaffic acid and its glycosides, which are denoted as A, B, C, D, E and F pfaffosides (Figure 1). ${ }^{1,8,9}$

The isolation methods described in the literature to obtain pfaffic acid from the roots of $P$. paniculata involve extraction with hot methanol, acid hydrolysis followed by partitioning between butanol and water and the purification of the organic fraction on a silica gel column. ${ }^{1,9}$ The presence of the pfaffosides in the crude extract requires the use of a hydrolysis step to release the aglycon (pfaffic acid); this hydrolysis is typically achieved by the addition of sulfuric acid in methanol.

The same extraction process was employed for the isolation of pfaffane-type nortriterpenoids, including pfaffic acid, from the roots of Pfaffia pulverulenta. ${ }^{11}$ Additionally, to obtain a dried extract enriched with pfaffic acid and/or pfaffosides with adaptogenic action, a patent was developed by the Instituto de Medicina Tropical de São Paulo (U.S. 5,449,516) ) $^{12}$ using the procedure described by Takemoto et al.. ${ }^{1}$

The aim of this work was to optimize the isolation and purification of pfaffic acid from the roots of $H$. eriantha to obtain a compound with a suitable degree of purity for analytical purposes.

*e-mail: rodney@cpqba.unicamp.br
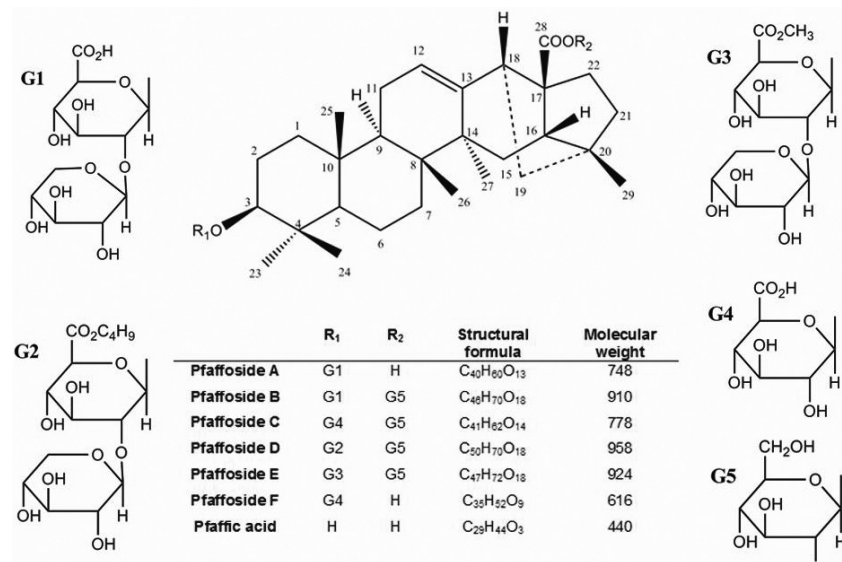

\begin{tabular}{ll}
$R_{1}$ & $R_{2}$ \\
\hline$G 1$ & $H$ \\
$G 1$ & $G 5$ \\
G4 & G5 \\
G2 & G5 \\
G3 & G5 \\
G4 & $H$ \\
$H$ & $H$
\end{tabular}

\begin{tabular}{cc}
$\begin{array}{c}\text { Structural } \\
\text { formula }\end{array}$ & $\begin{array}{c}\text { Molecular } \\
\text { weight }\end{array}$ \\
\hline $\mathrm{C}_{40} \mathrm{H}_{80} \mathrm{O}_{13}$ & 748 \\
$\mathrm{C}_{40} \mathrm{H}_{70} \mathrm{O}_{18}$ & 910 \\
$\mathrm{C}_{44} \mathrm{H}_{82} \mathrm{O}_{14}$ & 778 \\
$\mathrm{C}_{50} \mathrm{H}_{70} \mathrm{O}_{18}$ & 958 \\
$\mathrm{C}_{47} \mathrm{H}_{72} \mathrm{O}_{18}$ & 924 \\
$\mathrm{C}_{35} \mathrm{H}_{52} \mathrm{O}_{9}$ & 616 \\
$\mathrm{C}_{28} \mathrm{H}_{44} \mathrm{O}_{3}$ & 440
\end{tabular}

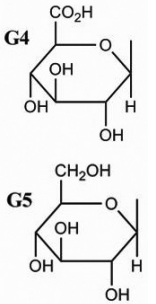

Figure 1. Structures of pfaffic acid and pfaffosides from H. eriantha. Adapted from ref. 10

\section{EXPERIMENTAL}

\section{Plant material}

Roots from Hebanthe eriantha, Amarantaceae, were collected in Silveiras, São Paulo State, Brazil. These plants were cultivated on CPQBA UNICAMP, and after one year of development, the plants were harvested in August, 2010, washed with water, crushed in a domestic processor and dried in an oven with forced air circulation at $40{ }^{\circ} \mathrm{C}$. The plant material was classified systematically by R. B. Torres from the Instituto Agronômico de Campinas (IAC). The voucher specimens were deposited and registered at the IAC herbarium under the number IAC 50213.

\section{Chemicals}

The solvents used for the isolation and purification were of analytical and HPLC grades, respectively. The water used for the mobile phase was purified using a Simplicity ${ }^{\circledR}$ system (Millipore ${ }^{\mathrm{TM}}$, São Paulo, Brazil), and methanol was of HPLC grade. 


\section{Apparatus}

The nuclear magnetic resonance spectra were obtained on a Bruker ${ }^{\mathrm{TM}}$ instrument $\left({ }^{1} \mathrm{H}: 400 \mathrm{MHz},{ }^{13} \mathrm{C}, 100 \mathrm{MHz}\right)$ using $\mathrm{CDCl}_{3}$ as solvent and TMS as an internal reference. The infrared spectra (IR) were obtained in $\mathrm{KBr}$ on a Spectrum One ${ }^{\circledR}$ FT-IR spectrometer (Perkin-Elmer ${ }^{\mathrm{TM}}$ ). The high-resolution ESI-MS spectra were obtained by direct insertion of the sample into a Micromass Q-TOF ${ }^{\circledR}$-electrospray ionization instrument operating in positive mode. The measurement of optical rotation $[\alpha]_{D}$ was performed in a Perkin-Elmer ${ }^{\mathrm{TM}} 341$ polarimeter using a $0.72 \mathrm{mg} \mathrm{mL}^{-1}$ solution in chloroform, and the reading taken at $589 \mathrm{~nm}$ with an $\mathrm{NaCl}$ lamp. The melting point $(\mathrm{mp})$ was determined in an Electrothermal ${ }^{\circledR}$ apparatus.

\section{Optimized process for pfaffic acid isolation}

The procedure employed for pfaffic acid isolation involved pfaffoside extraction from $H$. eriantha roots followed by acid hydrolysis to release the aglycon (pfaffic acid). Purification steps using classical column chromatography and semi-preparative HPLC were then conducted.

The dried and crushed roots $(60 \mathrm{~g})$ were subjected to extraction at reflux using $80 \%$ ethanol $(500 \mathrm{~mL})$ over $4 \mathrm{~h}$. After extraction, the material was filtered under vacuum and re-extracted under the same conditions. The extracts were combined, and the solvent was removed in an evaporative rotator under vacuum to obtain a crude extract.

This extract was hydrolyzed at reflux with $250 \mathrm{~mL}$ of $6 \%$ hydrochloric acid for $4 \mathrm{~h}$. The system was not heated above $120^{\circ} \mathrm{C}$ to avoid degradation of the sample. The crude hydrolyzed extract was partitioned twice with $200 \mathrm{~mL}$ of ethyl acetate, and the organic phases were combined and dried in an evaporative rotator under vacuum. The obtained residue was further purified using classical column chromatography.

The fractionation of the sample was performed on a chromatographic column of silica gel $60(0.063-0.200 \mathrm{~mm})$ at a sample/ stationary phase ratio of $1: 12(\mathrm{w} / \mathrm{w}) ; 50 \mathrm{~mL}$ fractions were collected. The column was packed with n-hexane and eluted with a mixture of n-hexane/ethyl acetate (70:30, v/v). Fractions F28 to F38 showed a single band by TLC analysis that was identified as pfaffic acid by GC-MS after methylation with diazomethane. These fractions were combined and dried under vacuum to give an amorphous solid with a light yellow color.

The solid obtained was subsequently purified by semi-preparative HPLC on a Waters ${ }^{\mathrm{TM}}$ system equipped with a Delta $600^{\circledR}$ quaternary pump, a Waters ${ }^{\mathrm{TM}} 2996$ diode array detector (monitoring at $210 \mathrm{~nm}$ ), a Waters ${ }^{\mathrm{TM}}$ Fraction Collector III and Empower ${ }^{\circledR}$ software. A SunFire ${ }^{\circledR}$ Prep C-18 OBD (100 mm x 19 mm i.d., 5 $\mu \mathrm{m}$; Waters ${ }^{\mathrm{TM}}$, USA) column was used. Methanol/formic acid $0.1 \%$ (90:10, v:v) was used as the mobile phase with a flow rate of 18

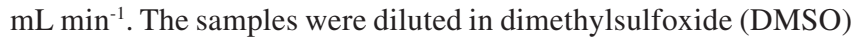
to approximately $125 \mathrm{mg} \mathrm{mL}^{-1}$, and $1.0 \mathrm{~mL}$ was injected into the HPLC. Five fractions were collected, corresponding to the middle portion of the pfaffic acid peak, and evaporated under vacuum to yield $244 \mathrm{mg}$ of purified compound.

\section{Thin layer chromatography (TLC)}

Fractions and extracts were analyzed on TLC $60 \mathrm{~F}_{254}$ aluminum sheets $\left(\right.$ Merck $\left.^{\mathrm{TM}}\right)$ using ethyl acetate as the mobile phase. After elution, the sheet plate was examined under UV light $(254,366 \mathrm{~nm})$ and sprayed with p-anisaldehyde followed by heating $\left(100-105^{\circ} \mathrm{C}\right)$ for $5 \mathrm{~min}$ for visualization.

\section{GC-MS analysis}

Fractions containing pfaffic acid were analyzed by GC-MS after methylation with diazomethane solution. Analyses were performed using an Agilent ${ }^{\mathrm{TM}} 6890 \mathrm{~N}$ gas chromatograph-mass spectrometer fitted with a fused methyl silicon HP-5MS column (30 m x $0.25 \mathrm{~mm}$ i.d., $0.25 \mu \mathrm{m}$ film thickness). Helium was used as the carrier gas at a flow rate of $1.0 \mathrm{~mL} \mathrm{~min}^{-1}$. The oven temperature was kept at $110^{\circ} \mathrm{C}$ for $2 \mathrm{~min}$, programmed to rise to $280{ }^{\circ} \mathrm{C}$ at a rate of $5{ }^{\circ} \mathrm{C} \mathrm{min}-1$ and then kept constant for $26 \mathrm{~min}$. The injector temperature was $250{ }^{\circ} \mathrm{C}$, and the split ratio was adjusted to 1:30. The mass spectral data were obtained at the following conditions: ionization potential, $70 \mathrm{eV}$; detector temperature, $300{ }^{\circ} \mathrm{C}$; and solvent delay, $3 \mathrm{~min}$. The samples were solubilized in ethyl acetate to a concentration of $20 \mathrm{mg} \mathrm{L}^{-1}$ and injected into the gas chromatograph.

\section{Chromatographic purity determination}

Chromatographic purity was measured on an Alliance ${ }^{\circledR}$ LCDAD-MS system (Waters ${ }^{\mathrm{TM}}$, USA) equipped with a Symmetry ${ }^{\circledR}$ C18 column ( $75 \times 4.6 \mathrm{~mm} ; 3.5 \mu \mathrm{m}$, Waters $\left.{ }^{\mathrm{TM}}\right)$ at $35^{\circ} \mathrm{C}$ using $0.1 \%$ formic acid and methanol $(18: 82, \mathrm{v}: \mathrm{v})$ as the mobile phase at a flow

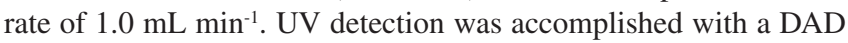
at $210 \mathrm{~nm}$. Mass spectra were obtained using a 3100 Waters $^{\mathrm{TM}}$ detector (single quadrupole) equipped with an ESI source operating in negative mode. For ESI, the best conditions were found to be an ionization voltage of $2.05 \mathrm{kV}$, a cone voltage of $150 \mathrm{~V}$ and an extractor voltage of $2 \mathrm{~V}$. Nitrogen was employed as a desolvation gas at $500 \mathrm{~L}$ $\mathrm{h}^{-1}$. The source and desolvation temperatures were 120 and $300{ }^{\circ} \mathrm{C}$, respectively. The analyzed samples were prepared in the eluent at a concentration of approximately $200 \mu \mathrm{g} \mathrm{mL}^{-1}$, and $20 \mu \mathrm{L}$ was injected into the chromatograph.

\section{RESULTS AND DISCUSSION}

The process to obtain pfaffic acid from the roots of $H$. eriantha (Poir.) Pedersen was evaluated using different extraction techniques (Soxhlet, reflux and turbo-extraction). Turbo-extraction was accomplished at room temperature. For extraction, methanol and 80 and $96 \%$ ethanol were evaluated as extraction solvents, as suggested by several authors, for different time periods..$^{911,12}$

After filtration and organic solvent evaporation, a dried crude extract was obtained. Hydrolysis of this crude extract was optimized in acidic medium to release the aglycon (pfaffic acid) using different hydrochloric acid concentrations and reflux times (5-15\%, 4-6 h) (Table 1).

According to data presented in Table 1, of all the techniques studied, turbo-extraction returned the highest yield of dry mass. However, extract partitioning with ethyl acetate led to emulsion formation after hydrolysis, making this method of isolation unfeasible. The greater efficiency of turbo-extraction was due to cell disruption, but this also led to the extraction of a greater number of interfering compounds.

The realization of simultaneous extraction and hydrolysis resulted in 8.3 and $12.8 \%$ yields of dry mass ( $F$ and G, respectively), which were approximately 5 times greater than the yield obtained by alcoholic and hydroalcoholic extraction. However, the use of acidified aqueous medium led to large amounts of foam and strong browning due to sample degradation when $10 \% \mathrm{HCl}$ was used.

The compositions of all the crude hydrolyzed extracts (except E) were evaluated by TLC analysis. A violet band was observed in the upper third of the chromatogram that was later confirmed to be pfaffic acid by GC-MS analysis after methylation with diazomethane. The 
Table 1. Preliminary tests for extraction yields in dry mass using hydrolysis steps separately and simultaneously

\begin{tabular}{|c|c|c|c|c|c|}
\hline \multirow[b]{2}{*}{ Tests } & \multicolumn{2}{|l|}{ Extraction } & \multicolumn{2}{|c|}{ Hydrolysis* } & \multirow{2}{*}{$\begin{array}{l}\text { Dry mass } \\
\text { overall yield } \\
\qquad \%)\end{array}$} \\
\hline & conditions & $\begin{array}{c}\text { yield } \\
(\%)\end{array}$ & conditions & $\begin{array}{l}\text { yield } \\
(\%)\end{array}$ & \\
\hline A & Soxhlet, 12 h, $96 \%$ EtOH & 12.5 & $\begin{array}{l}15 \% \mathrm{HCl}, \\
\text { reflux, } 6 \mathrm{~h}\end{array}$ & 23.8 & 2.98 \\
\hline B & Reflux, 4 h, 96\% EtOH & 7.9 & $\begin{array}{l}15 \% \mathrm{HCl}, \\
\text { reflux, } 5 \mathrm{~h}\end{array}$ & 30.6 & 2.42 \\
\hline $\mathrm{C}$ & Reflux, 4 h, $\mathrm{MeOH}$ & 9.5 & $\begin{array}{l}15 \% \mathrm{HCl}, \\
\text { reflux, } 5 \mathrm{~h}\end{array}$ & 29.2 & 2.77 \\
\hline $\mathrm{D}$ & Reflux, 4 h, $80 \%$ EtOH & 7.2 & $\begin{array}{l}6 \% \mathrm{HCl}, \\
\text { reflux, } 4 \mathrm{~h}\end{array}$ & 30.5 & 2.20 \\
\hline $\mathrm{E}$ & $\begin{array}{c}\text { Turbo-extraction, room } \\
\text { temperature, } 5 \text { min, } 80 \% \\
\text { EtOH }\end{array}$ & 20.9 & $\begin{array}{c}15 \% \mathrm{HCl} \\
4 \mathrm{~h}\end{array}$ & $\mathrm{nd}^{* *}$ & - \\
\hline \multicolumn{6}{|c|}{ Simultaneous Extraction and Hydrolysis } \\
\hline $\mathrm{F}$ & Reflux, 4 & h, $5 \%$ & $\mathrm{HCl}$ & & 12.8 \\
\hline $\mathrm{G}$ & Reflux, 4 & n, $10 \%$ & $\mathrm{HCl}$ & & 8.3 \\
\hline
\end{tabular}

*After hydrolysis, all tests were partitioned with ethyl acetate. **nd: not determined due to emulsion formation.

chromatogram obtained with test $\mathrm{D}$ showed the most intense band corresponding to pfaffic acid, so the use of hydroalcoholic medium at reflux for $4 \mathrm{~h}$ was adopted as the preferred isolation method.

The crude hydrolyzed extract was then fractionated, and $50 \mathrm{~mL}$ fractions were collected from a silica gel column using n-hexane/ ethyl acetate (70:30, v/v) as the mobile phase. After TLC analysis, the samples were combined according to their chemical profiles and dried under vacuum to obtain 7 samples (GF1-GF7). The amount obtained for each fraction was $506 \mathrm{mg}$ (GF1), $78 \mathrm{mg}$ (GF2), $93 \mathrm{mg}$ (GF3), $580 \mathrm{mg}$ (GF4), $383 \mathrm{mg}$ (GF5), $735 \mathrm{mg}$ (GF6) and $448 \mathrm{mg}$ (GF7). TLC analysis of the samples revealed the presence of pfaffic acid as a single band in GF4. After solvent evaporation, a faintly yellow amorphous solid was obtained.

GC-MS analysis of GF4 was performed and revealed a major signal at 47 min with a mass spectrum characteristic of methylated pfaffic acid (454 Da molecular ion and a 246 Da base peak). The GF4 sample was then purified by semi-preparative HPLC, in which the middle part of the pfaffic acid peak was collected (retention time $4.5 \mathrm{~min}, \mathrm{k}=3.1$ ). After removing the solvent under vacuum, a white amorphous solid was obtained at a $42 \%$ yield.

Confirmation of the chemical structure was achieved by comparing the melting point, optical rotation, high-resolution mass spectrum, infrared spectrum, ${ }^{1} \mathrm{H}$ NMR, ${ }^{13} \mathrm{C}$ NMR, COSY, DEPT, HSQC and $\mathrm{HMBC}$ to data reported by Shiobara et al. ${ }^{11}$ The purified pfaffic acid (Figure 1) displayed a melting point in the range of 279-281.5 ${ }^{\circ} \mathrm{C}[\alpha]_{\mathrm{D}}^{22}+84.9\left(0.72 \mathrm{mg} \mathrm{mL}^{-1}, \mathrm{CHCl}_{3}\right)$. The ESI-MS mass spectrum in the positive mode showed the protonated molecular ion at $\mathrm{m} / 2$ 440.3283, which corresponded to the molecular formula $\mathrm{C}_{29} \mathrm{H}_{44} \mathrm{O}_{3}$. The IR spectrum showed characteristic absorptions at $v_{\max } \mathrm{cm}^{-1} 3420$ $(\mathrm{OH}), 1689(\mathrm{C}=\mathrm{O}), 1631(\mathrm{C}=\mathrm{C}), 1328,1118$ and 1078, which were in agreement with literature data. ${ }^{1,9}$

The ${ }^{1} \mathrm{H}$ NMR spectrum showed five methyl singlets at $\delta \mathrm{H} 1.319$, $1.180,0.984,0.898,0.764$ and $0.722 \mathrm{ppm}$, a double doublet at $3.22 \delta$ $\mathrm{H}$ for carbinolic hydrogen $\mathrm{H} 3$ and a deformed triplet at $\delta 5.23$, which corresponded to the $\mathrm{H} 12$ olefinic hydrogen. The ${ }^{13} \mathrm{C}$ NMR spectrum showed 29 carbons, and comparative analysis of ${ }^{13} \mathrm{C}$ NMR DEPT (Distortionless Enhancement by Polarization Transfer) confirmed the presence of $9 \mathrm{CH}_{2}, 6 \mathrm{CH}_{3}, 6 \mathrm{CH}$ and $8 \mathrm{CO}$ (quaternary carbons), which matched the expected structure of pfaffic acid. The assignment of hydrogen and carbon chemical shifts was performed through an evaluation of the ${ }^{13} \mathrm{C}$ NMR HMBC (Heteronuclear Multiple Bond Correlation), ${ }^{13} \mathrm{C}$ HSQC NMR (Heteronuclear Single Quantum Coherence) and $1 \mathrm{H}$ NMR COSY (Correlate Spectroscopy) spectra (Table 2). The acid and olefin groups were assigned to $\delta \mathrm{C} 180.93$ $\left(\mathrm{CO}_{2} \mathrm{H}\right), 144.45(=\mathrm{C}-13)$ and $120.26(=\mathrm{HC}-12) \mathrm{ppm}$, and the signal for a methylenic sp ${ }^{2}$ hydrogen at $\delta \mathrm{H} 5.23$ (sl) was present in the ${ }^{1} \mathrm{H}$ NMR spectrum. ${ }^{11}$

Table 2: ${ }^{1} \mathrm{H}$ and ${ }^{13} \mathrm{C}$ NMR data of the isolated pfaffic acid ( $\mathrm{CDCl}_{3}$, TMS). Chemical shifts are in ppm $\left(\delta_{\mathrm{H}} \mathrm{e} \delta_{\mathrm{C}}\right)$, and $(\mathrm{J})$ is in $\mathrm{Hz}^{*}$

\begin{tabular}{|c|c|c|c|c|}
\hline & \multirow{2}{*}{$\delta_{\mathrm{H}}$} & \multirow{2}{*}{$\delta_{\mathrm{C}}$} & \multicolumn{2}{|r|}{ HMBC } \\
\hline & & & ${ }^{2} \mathrm{~J}_{\mathrm{CH}}$ & ${ }^{3} \mathrm{~J}_{\mathrm{CH}}$ \\
\hline $\mathrm{CH}-1$ & $\begin{array}{l}\mathrm{H} 1 \alpha 0.98 \\
\mathrm{H} 1 \beta 1.55\end{array}$ & 38.90 & $\mathrm{H}-2$ & H-5; H-25 \\
\hline $\mathrm{CH}-2$ & $\begin{array}{l}\mathrm{H} 2 \alpha 1.50(\mathrm{~m}) \\
\mathrm{H} 2 \beta \quad 1.60(\mathrm{~m})\end{array}$ & 27.17 & $\mathrm{H}-1$ & H-4; H-10 \\
\hline $\mathrm{CH}-3$ & $\begin{array}{c}3.22(\mathrm{dd}, 10.76 \\
4.44)\end{array}$ & 79.04 & - & $\mathrm{H}-23 ; \mathrm{H}-24$ \\
\hline C-4 & - & 38.78 & $\begin{array}{l}\text { H-5; H-23; } \\
\text { H-24 }\end{array}$ & H-2; H-6 \\
\hline $\mathrm{CH}-5$ & 0.72 & 55.31 & H-6 & $\begin{array}{c}\mathrm{H}-1 ; \mathrm{H}-7 ; \mathrm{H}-9 ; \mathrm{H}-23 ; \\
\mathrm{H}-24 ; \mathrm{H}-25\end{array}$ \\
\hline $\mathrm{CH}-6$ & $\begin{array}{l}\mathrm{H} 6 \alpha 1.56 \\
\mathrm{H} 6 \beta 1.38\end{array}$ & 18.22 & $\mathrm{H}-5 ; \mathrm{H}-7$ & H-26 \\
\hline $\mathrm{CH}-7$ & $\begin{array}{l}\mathrm{H} 7 \alpha 1.46 \\
\mathrm{H} 7 \beta 1.30\end{array}$ & 31.57 & H-6 & H-5; H-26 \\
\hline C-8 & - & 39.66 & H-7; H-26 & H-6; H-11; H-27 \\
\hline $\mathrm{CH}-9$ & $1.58(\mathrm{~m})$ & 47.31 & $\mathrm{H}-11$ & H-5; H-7; H-25; H-26 \\
\hline $\mathrm{C}-10$ & - & 37.03 & H-5; H-25 & $\mathrm{H}-2 ; \mathrm{H}-6 ; \mathrm{H}-11$ \\
\hline $\mathrm{CH}-11$ & $\begin{array}{l}\mathrm{H} 11 \alpha 1.65 \\
\mathrm{H} 11 \beta 1.90\end{array}$ & 23.02 & H-9; H-12 & H-8; H-10; H-13 \\
\hline $\mathrm{CH}-12$ & $5.23 \mathrm{td}$ & 120.26 & H-11 & H-18; \\
\hline $\mathrm{C}-13$ & - & 144.45 & $\mathrm{H}-18$ & H-11; H-19;H-27 \\
\hline $\mathrm{C}-14$ & - & 40.14 & $\mathrm{H}-27$ & H-7; H-16;H-18;H-26 \\
\hline $\mathrm{CH}-15$ & $\begin{array}{l}\mathrm{H} 15 \alpha 1.24 \\
\mathrm{H} 15 \beta 2.00\end{array}$ & 28.42 & H-16 & $\mathrm{H}-27$ \\
\hline $\mathrm{CH}-16$ & $1.80 \mathrm{dd}$ & 51.10 & - & $\begin{array}{c}\text { H-18; H-19; H-21; } \\
\text { H-22 }\end{array}$ \\
\hline $\mathrm{C}-17$ & - & 55.61 & $\begin{array}{l}\text { H-16; H-18; } \\
\text { H-22 }\end{array}$ & H-19; H-21; \\
\hline $\mathrm{CH}-18$ & $2.56 \mathrm{dd}$ & 51.51 & H-19 & H-16; H-22; H-29 \\
\hline $\mathrm{CH}-19$ & 1.55 e 0.95 & 38.42 & $\mathrm{H}-18$ & H-16; H-21; H-29 \\
\hline $\mathrm{C}-20$ & - & 44.39 & $\begin{array}{l}\text { H-16; H-19; } \\
\text { H-21; H-29 }\end{array}$ & H-18; H-22; H-29 \\
\hline $\mathrm{CH}-21$ & 1.70 e 1.40 & 41.08 & $\mathrm{H}-22$ & H-16; H-19; H-29 \\
\hline $\mathrm{CH}-22$ & & 33.54 & $\mathrm{H}-21$ & H-16; H-19 \\
\hline $\mathrm{CH}-23$ & $0.98 \mathrm{~s}$ & 28.03 & - & H-3; H-5; H-24 \\
\hline $\mathrm{CH}-24$ & $0.72 \mathrm{~s}$ & 15.55 & - & H-3; H-5; H-23 \\
\hline $\mathrm{CH}-25$ & $0.89 \mathrm{~s}$ & 15.18 & - & H-1; H-5; H-29 \\
\hline $\mathrm{CH}-26$ & $0.76 \mathrm{~s}$ & 16.32 & - & H-7 \\
\hline $\mathrm{CH}-27$ & $1.34 \mathrm{~s}$ & 29.87 & - & - \\
\hline $\mathrm{C}-28$ & - & 180.93 & - & H-18; H-19; H-22 \\
\hline $\mathrm{CH}-29$ & $1.18 \mathrm{~s}$ & 18.34 & - & $\mathrm{H}-21$ \\
\hline
\end{tabular}

*The number of hydrogens attached to carbon was deduced based on the DEPT spectra.

The observed variations in the chemical shifts of the carbons and hydrogens were due to the previously reported spectrum being acquired at $100 \mathrm{MHz}$ in deuterated pyridine. ${ }^{11}$ The various techniques used allowed the assignment of the chemical shifts of pfaffic acid. 
The analysis of pfaffic acid by LC-DAD revealed a chromatographic purity of $98.5 \%$ determined at $210 \mathrm{~nm}$, and mass spectrometry detection by ESI in negative mode confirmed this purity. Figure 2 shows the chromatograms obtained from these two methods and the mass spectrum of pfaffic acid.
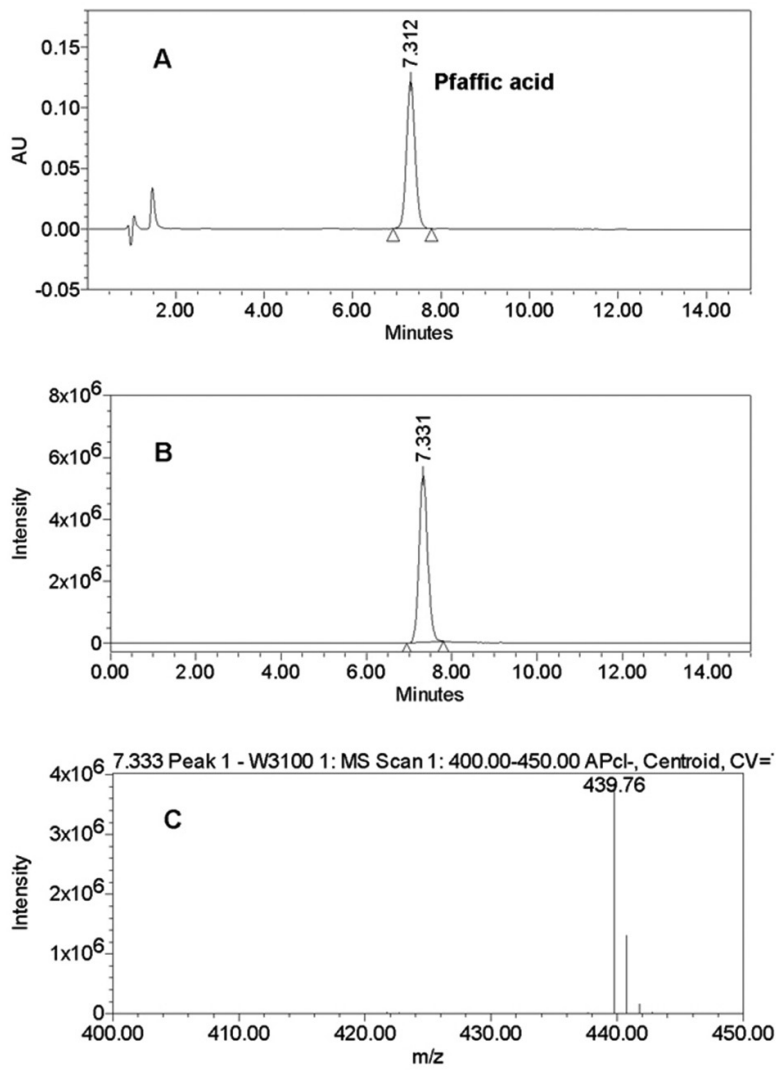

Figure 2. LC-DAD-ESI-MS analysis for purified pfaffic acid (200 $\left.\mu \mathrm{g} \mathrm{mL}^{-1}\right)$. (A) chromatogram obtained at $210 \mathrm{~nm}$; (B) chromatogram obtained from ESI-MS detection (scan mode) in negative mode with the mass spectrum for the pfaffic acid peak $(C)$

The isolation of pfaffic acid from H. eriantha roots involved four steps: extraction in hydroalcoholic medium, acid hydrolysis, column chromatography fractionation and purification by semi-preparative HPLC. This procedure afforded a pfaffic acid yield of $0.25 \%$, which is at least 40 times higher than the yield described by Takemoto et al.. ${ }^{1}(0.006 \%)$

\section{CONCLUSIONS}

The process of pfaffic acid isolation reported here was efficient $(0.25 \%$ yield $)$ and led to the isolation of a solid with a purity that was suitably high for analytical purposes (98.5\% HPLC purity). Additionally, this study has contributed further spectroscopic data on the compound of interest that arose from the use of more sophisticated NMR techniques.

\section{REFERENCES}

1. Takemoto, T.; Nishimoto, N.; Nakai, S.; Takagi, N.; Hayashi, S.; Odashima, S.; Wada, Y.; Tetrahedron Lett. 1983, 24, 1057.

2. http://www.usp.br/agen/repgs/2005/imprs/257.htm, accessed March 2013.

3. Pinello, K. C.; Fonseca, E. S. M.; Akisue, G.; Silva, A. P.; Oloris, S. C. S.; Sakai, M.; Matsuzaki, P.; Nagamime, M. K.; Palermo Neto, J.; Dagli, M. L. Z.; Life Sci. 2006, 78, 1287.

4. Fernandes, J. F. O.; Brito, L. C.; Frydman, J. N. G.; Santos-Filho, S. D.; Bernardo-Filho, M.; Braz. J. Pharmacog. 2005, 15, 126.

5. Vigo, C. L. S.; Narita, E.; Nakamura, C. V.; Marques, L. C.; Rev. Bras. Farmacogn. 2003, 32, 14.

6. Watanabe, T.; Watanabe, M.; Watanabe, Y.; Hotta, C.; Cancer Detect. Prev. 2000, 24, 173.

7. D’Angelo, A.; Grimaldi, R.; Caravaggi, M.; Marcoli, M.; Perucca, E.; Lecchini, S.; Frigo.; G. M.; Crema, A.; J. Ethnopharmacol. 1986, 16, 15 .

8. Nakai, S.; Takagi, N.; Miichi, H.; Hayashi, S.; Nishimoto, N.; Takemoto, T.; Kizu, H.; Phytochemistry 1984, 23, 1703.

9. Nishimoto, N.; Nakai, S.; Noriko T.; Hayashi, S.; Takemoto, T.; Odashima, S.; Kizu, H.; Wada Y.; Phytochemistry 1984, 23, 139.

10. Oliveira, F.; Rev. Bras. Farmacogn. 1986, 1, 86.

11. Shiobara, Y.; Inoue, S. S; Nishiguchi, Y.; Kato, K.; Takemoto, T.; Nishimoto, N.; Oliveira, F.; Akisue, G.; Akisue, M. K.; Hashimoto, G.; Phytochemistry 1992, 31, 1737.

12. http://www.patentstorm.us/patents/5449516.html, accessed March 2013. 